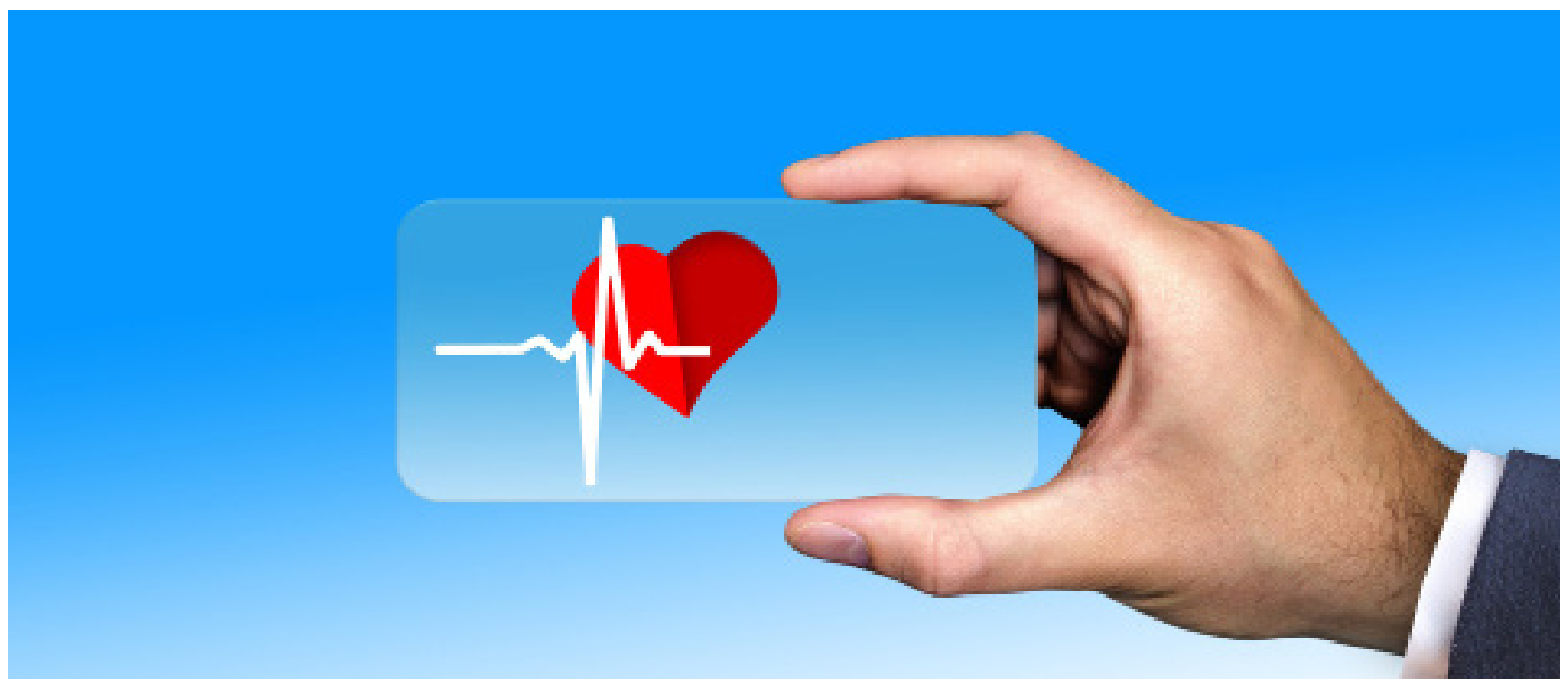

\title{
Responsabilidad civil de la práctica médica
}

\section{Civil Responsibility of Medical Practice}

\section{Enrique De Valencia-Vélez}

Especialista, enriquepdevalencia@hotmail.com, https://orcid.org/0000-0002-5459-9050, Docente investigador.

Centro de Investigaciones Científicas y Tecnológicas de (CICTAR),

Cartagena de Indias, Colombia.

\section{Martha Benítez-Izquierdo}

Especialista, matha.benitez@hotmail.com,

https://orcid.org/0000-0002-6391-5094, Docente investigadora.

Centro de Investigaciones Científicas y Tecnológicas de (CICTAR),

Cartagena de Indias, Colombia 


\section{6}

Recibido:

Marzo 10 de 2018

Aceptado: junio 20 de 2018

Cómo citar: E.De Valencia-Vélez y M. Benítez-Izquierdo, "Responsabilidad civil de la práctica médica", Sostenibilidad, Tecnología y Humanismo, vol. 9, no. 2, 65-72, 2018.

Resumen

En el presente trabajo presentaremos el tema de la responsabilidad civil de la práctica médica y hospitalaria, este daño provocado por el acto médico genera a favor de la víctima, o sea, el paciente una indemnización por el perjuicio causado, en el entendido que las responsabilidad es el sinónimo de responder, en este caso a los daños causados a otros. Estableceremos si el acto médico o contrato médico es uno de aquellos que tienen obligación de medio u obligación de resultado, partiendo de la premisa que la responsabilidad data de la consecuencia entre un contrato de obligación y el derecho correspondiente, de igual manera, de mostrar como a nivel jurídico se determinan si dicha responsabilidad es contractual 0 por el contrario es extracontractual, así mismo se mostraran las vías judiciales para el reclamo respectivo y las leyes pertinentes para tal fin, este artículo permite mostrar una visión analítica y crítica sobre las posturas que ha asumido la jurisprudencia y contencioso administrativa en materia de responsabilidad civil de la práctica médica, por último, se podrá comprender la relación entre una obligación y un derecho, y las respectivas leyes que le rige.

Palabras clave: Acto médico, daño, indemnización, práctica médica hospitalaria, responsabilidad civil contractual, responsabilidad civil extracontractual.
Abstract

The main purpose of this document is to demonstrate possibilities with real data, and technical specifications of commercial automation systems, (traditional and emerging) to the microentrepreneur so that it can update the automated processes, of non-automated machinery, to extend its useful life and lower their costs, and include in these technological updates local human capital, so as not to have to acquire new machinery using the most appropriate technologies for each process and for each economic situation in particular, the emerging nature of the technology leads to the search for the best technological tool, which allows usufruct of resources such as the time factor, the economy and the professional workforce, the constant search of companies to be leaders in their field makes them mandatory that they innovate in the tools informatics taking advantage of their benefits; consequently, this article is sectioned as follows; in the first section a review of the traditional and emerging markets and technologies is made to select technologies that represent the comparison object of this article; In the second session, the most representative technical data of the selected technologies are reviewed.

Keywords: Medicalact, damage, compensation, hospital medical practice, contractual civil liability, non-contractual civil liability. 
Introducción

Autores como [1] señalan que La calificación global de percepción, permite concluir que alrededor del $50 \%$ de los pacientes tienen percepciones bajas en las dimensiones evaluadas de calidad de los servicios médicos prestados; es por ello que el menoscabo a la integridad física y psicológica del paciente provocada por un acto médico, constituye la fuente para que aparezca con todo rigor la responsabilidad civil de la práctica médica y hospitalaria, este daño provocado por el acto médico genera a favor de la víctima, o sea, el paciente una indemnización por el perjuicio causado. "La profesión médica es una actividad digna, honorada y decorosa que requiere una especial vocación de servicio y exige del médico una gran responsabilidad individual hacia su paciente y una responsabilidad colectiva hacia el grupo social donde ejerce" [2].

Así mismo, es importante hacer destacar que como ser humano no se está exento del equivoco o error al momento de su praxis en su ámbito profesional, el profesional de la medicina tiene un activo intangible como lo es el conocimiento de su área y las implicaciones que conlleve al mal uso de las mismas "el conocimiento es un activo intangible que las personas y organizaciones no saben cuidar ni mucho menos valorar teniendo resultados importantes en cualquier gestión, hasta en la propia de cada persona" [3], el desconocimiento de la normativa tampoco lo exime de las consecuencias de lo erróneo de algún proceso.

De igual modo, la responsabilidad civil de la práctica médica puede ser contractual o extracontractual, dependiendo si el acto médico se realiza en desarrollo de un contrato o por fuera del mismo; si estamos hablando de responsabilidad médica contractual, tendremos que establecer si el acto médico o contrato médico es uno de aquellos que tienen obligación de medio u obligación de resultado. "La responsabilidad civil es la obligación de reparar el daño causado a una persona, sea por culpa, sea en ciertos casos determinados por la ley, por el riesgo resultante de la actividad" [4].

Como seres humanos no se está exento de cometer errores, "el error es perfectamente lógico en cualquier actividad humana y la medicina no está exenta de éste, no es infalible" [5]; sin embargo, entre el error y la mala praxis hay una gran brecha, en el entendido de que dicho profesional resguarda nada más importante que la vida de un ser viviente, por lo tanto, siempre se dará una exigencia de un médico con las competencias adecuadas para tal fin; por ende bajo sus hombro reposa la responsabilidad de resguardar la vida del paciente o en su defecto hacer los procesos pertinentes para la salvaguarda de los mismos, en el presente trabajo se definen la responsabilidad contractual y extracontractual, las reyes regentes y las responsabilidades al respecto.

\section{La Responsabilidad Social.}

La doctrina moderna afirma que ya casi no tiene sentido que se continúe haciendo la distinción entre responsabilidad contractual y responsabilidad extracontractual (o aquiliana); pero lo cierto es que, hoy por hoy, sigue vigente ese esquema en nuestra propuesta normativa legal condensada en el Código civil, con diferentes reglas [6].

En Colombia la ley 100 de 1993, desarrolló un sistema de salud montado en un régimen contributivo y un régimen subsidiado, y a futuro debería existir cobertura total, es decir, la práctica médica extracontractual es muy raro que ocurra porque lo normal es que la gente utilizando la seguridad social llegue al servicio médico, pero eventualmente se nos 


\section{8}

ocurre que puede existir una práctica médica extracontractual, cuando por ejemplo, un médico que se desplaza con su familia por una carretera, observa como un bus tiene un bus intermunicipal tiene un accidente en el que hay muchos heridos, el médico impulsado por su vocación comienza a atender a las personas siniestradas, en este ejemplo, se configuraría una práctica médica extracontractual y se tendría que establecer si el acto médico extracontractual es un acto peligroso o no.

Actualmente en Colombia la responsabilidad médica es de medio y no de resultado; es decir el galeno no está en la obligación de garantizar la salud del enfermo, pero sí de brindarle todo su apoyo en procura de su mejoría [5].

Por fortuna la jurisprudencia colombiana ha esclarecido el problema con jurisprudencias reiteradas en que se dice que la práctica médica extracontractual no es una actividad peligrosa y se rige por el art. 2341 del Código Civil el cual suscribe que la responsabilidad civil extracontractual es aquel que ha cometido un delito o culpa, que ha inferido daño a otro; ahora bien, los que no están de acuerdo con esta jurisprudencia, es decir, que están de acuerdo que sí es una actividad peligrosa, consideran que la salud es el bien más preciado que tiene un ser humano, y que por una vocación se realice un mal procedimiento médico no exime al galeno de estar realizando una actividad de por sí riesgosa y consideran que se debe presumir la responsabilidad del mismo en caso de daño.

De tal manera que la actuación del médico podrá provocar responsabilidad de orden civil, ya sea contractual o extra contractual [7]. Pero se analizará qué consecuencias procesales tendría considerar la práctica médica extracontractual una actividad peligrosa o no. El art. 2356 del C.C. del Código Civil establece: quien ponga en peligro a alguien y el cause un daño se presume su responsabilidad, por lo tanto, si la práctica médica extracontractual es una actividad peligrosa cuando comience el proceso el médico entra como presuntamente responsable del daño causado y lo único que lo exonera de responsabilidad es demostrar una "causa extraña", que según la jurisprudencia colombiana , causa extraña sería demostrar tres cosas: Culpa exclusiva de la víctima, culpa de un tercero y caso fortuito Y/o fuerza mayor, vemos que el paciente queda exonerado de la carga de la prueba, y que ésta que da en cabeza del demandado que sería el médico y que lo único que lo salvaría de no indemnizar económicamente al paciente sería comprobando una causal exhortativa de responsabilidad o causa extraña [8].

Ahora bien, si como lo ha dicho la Corte Suprema Justicia de Colombia: la práctica médica no es una actividad peligrosa entraríamos en lo preceptuado por el art. 2341 del Código Civil, en donde se establece una responsabilidad con culpa probada, es decir, que la carga probatoria la tendría el paciente, o sea, la víctima, quien tendría que probarle al médico su responsabilidad en la ocurrencia del hecho. De esta manera, el médico solamente probando diligencia y cuidado, quedaría exonerado de responsabilidad. La naturaleza jurídica de la relación médico-paciente es de orden civil al establecer que dicha relación es una obligación contractual [9].

Tratándose de responsabilidad médica contractual, hay que establecer si el contrato de práctica médica es de aquellos que tiene obligación de medio o es de aquellos que tiene obligación de resultado, si el contrato médico es de obligación de medio, la carga probatoria en un proceso la tendría el paciente, es decir, la víctima, a quien le tocaría probar la responsabilidad civil del médico. En cambio, si el contrato tiene obligación de resultado se 
presumiría la responsabilidad del médico y a éste le tocaría probar una causa extraña.

El ejercicio de la medicina es una profesión digna, honrada, decorosa, que requiere una especial vocación de servicio y exige del médico una gran responsabilidad individual [10].

Incumplimiento puro y simple por parte del médico.

Hay que aclarar que tratándose de un contrato de prestación de servicios médicos, el médico se presumirá responsable por el simple hecho del incumplimiento, es decir, si el médico incumple el contrato porque simplemente no se presenta el día de la operación a cumplir con el compromiso, ese incumplimiento genera una obligación de resultado y la consecuencia es que al médico le toca demostrar una causa extraña.

Ejemplo: si un médico se obliga con un paciente a practicarle una intervención quirúrgica un día determinado a una hora determinada y por una borrachera del médico incumple el compromiso aquí se configura una obligación de resultado por incumplimiento del contrato pactado; los médicos están en la obligación de asistir y atender a las personas cuya vida esté en peligro, independientemente del estado en que se encuentren, ya que el fin supremo es el respeto de la vida humana. Al médico le es exigible todo el cuidado que le sea posible emplear para la protección de la vida y la salud del paciente [2].

La culpa médica por defectuosa prestación del servicio.

Hay que distinguir, que una cosa es el incumplimiento del médico de su compromiso que sería el caso que acabamos de tratar y otra cosa es que realizado el acto médico éste quede defectuoso. En este caso es cuando aparece la distinción del contrato con obligación de medio y con obligación de resultado. ¿Cuál es el problema? quien tiene la carga de la prueba, el paciente o el médico, en la jurisprudencia y en la doctrina hay posiciones encontradas, trataré de explicar en los siguientes párrafos, las posiciones de nosotros y de otros; El médico en su actividad profesional, a través de la prestación de sus servicios profesionales, asume con el paciente una obligación, la cual, dentro de la clasificación general de las obligaciones es considerada una obligación de medio y no de resultado [10].

Para el tratadista el contrato médico se le debe aplicar las normas del mandato por expresa disposición del Código Civil, alega que qué carrera más larga la de la Medicina y en este caso, el Médico sería el Mandatario y el paciente el Mandante, a lo que agrega que cuando se realiza un acto médico se debe aplicar el art. 2184 del que dice: “...no podrá el mandante disculparse de cumplir estas obligaciones, alegando que el negocio alegado al Mandatario no haya tenido buen éxito o que pudo desempeñarse a menos costo; al contrato médico se le aplican las reglas del mandato, más no dice que el contrato médico no es un contrato de mandato, porque él bien sabe, que el contrato de mandato en sentido estricto implica realizar una labor eminentemente jurídica y en su libro cita a muchos autores que comparten esta opinión [11].

La jurisprudencia nacional ha limitado el alcance de esta norma, estimando que su aplicación únicamente procede cuando, junto con la prestación de servicios profesionales está presente la facultad de representación. el texto del artículo 2144 del C.C. no puede entenderse en el sentido disyuntivo que ofrecen sus términos, sino en el de la concurrencia del servicio con la representación de la persona a quien se presta; porque si el mandato supone esencialmente un acto jurídico de obligatoriedad para el mandante, resulta a que llegue a estructurarlo el simple servicio del 


\section{0}

médico que ejecuta una operación quirúrgica, o el mismo abogado que se encarga de la confección de una minuta, no obstante suponer tales servicios los dilatados estudios profesionales que supone el texto [11].

Jurisprudencia del consejo de estado.

Hay una práctica médica estatal que como consecuencia de un daño, la víctima demanda ante la jurisdicción contenciosa administrativa, el estado es prestador del servicio médico y por lo tanto, existe una responsabilidad civil estatal por la mala práctica médica. Así mismo, la mayoría de intervenciones quirúrgicas y tratamientos médicos implican obligaciones de medio, por cuanto suele existir incertidumbre frente a los resultados [12].

El Consejo de Estado desde el principio de los años 90 's ha mantenido una jurisprudencia que consiste que cuando haya una mala práctica médica por parte del estado, se considerará "falla del servicio", por lo tanto, se invierte la carga de la prueba y es al Estado que le toca probar una causa extraña. También el Consejo de Estado ha tenido fallos en que invierte la carga de la prueba sin necesidad de considerar que hubo falla en el servicio, es decir, aplica la teoría de la carga dinámica de la prueba, en que el demandado corre con la prueba y lo único que lo exonera de responsabilidad por una causa extraña.

Resumiendo la posición del Consejo de Estado, siempre está al lado de la víctima porque lo exonera de probar la falla de la práctica médica.

El hecho de la víctima es importante desde el punto de vista de la responsabilidad civil para exonerar, parcial o totalmente, el demandado que ha causado un daño, su influencia será determinada en la medida en que ese hecho haya sido causa exclusiva o parcial del perjuicio [13].
Postura jurisprudencia de la corte suprema de justicia.

La Corte Suprema de Justicia de Colombia, considera que el contrato de práctica médica es de obligación de medio, en términos generales, y en una famosa jurisprudencia del año 2001 que se ha mantenido hasta la fecha, considera, no obstante lo anterior, que hay tres contratos Médicos, que son de resultados, estos son: el de ginecología y obstetricia, cirugía estética y cada vez que el médico prometa un resultado. En la práctica de la medicina existen ocasiones donde el médico debe tomar decisiones en cualquier circunstancia que comprometa al paciente y que pocas veces se pregunta si su decisión traerá consecuencias a su carrera y al paciente en el caso de ser una acción perjudicial [14]. Los conceptos de daño e indemnización han ido cambiando a lo largo de los años, pero las modificaciones más significativas en los sistemas de normas de responsabilidad médica se producen como consecuencia de las actuales estructuras sanitarias, la creciente complejidad de las terapias, las nuevas formas de prestación de servicios $y$, consecuentemente, a partir del incremento del número de reclamaciones [15].

El de Ginecología y obstetricia, ha dicho la Corte, que no es lógico que un médico que está tratando una paciente durante 9 meses. El parto o el embarazo tenga problemas, y por lo tanto, es a él, el Médico Ginecólogo, quien le toca probar la causa extraña; la falta de un desenlace satisfactorio del mismo da lugar a una responsabilidad de resultado del médico tratante y de la institución de salud, puesto que la terminación esperada de la actividad materno infantil en tales casos es el parto normal [12].

En la cirugía estética con mucha más razón es el esteticista a quien le corresponde probar por qué la nariz o los senos del paciente 
quedaron defectuosos. Lo haría obviamente demostrando una causal exagerativa de responsabilidad, Esto convierte al acto médico no de medio, sino de resultados porque el médico es quien lo está prometiendo, y por lo tanto, es al galeno quien tiene que probar por qué no es responsable del daño ocasionado en el paciente. La responsabilidad civil profesional del médico es su deber de reparar el daño que causó durante el ejercicio de su profesión. Dicho daño puede haberse debido a negligencia, imprudencia o impericia del profesional durante su actuar, al faltar a sus obligaciones esenciales [15].

\section{Conclusiones}

Definitivamente la practica médica es tal vez sin dudarlo una de las profesiones más importante, puesto que en las manos de los médicos reposa la vida de un ser humano, su resguardo y salva guarda, si bien es cierto, que los mismo son humanos y como tal no están exentos de cometer algún error, también lo es que los mismos se forman con principios y normas para salvaguardar y mejora la condiciones de salud de los pacientes; por tanto, siempre abra un lazo entre paciente y médico, este sería por vinculación a la medicina.

El médico tiene claro que la praxis en sus pacientes en mal termino conlleva a una serie de penalidades a fin de esclarecer los sucesos y conseguir la culpa, es aquí en donde la jurisprudencia y la doctrina entran fungen como las vías legales para la resolución de cualquier altercado, hoy en día el paciente ha cobrado más importancias, tal vez por los múltiples procesos que no han resultado de buena manera, y a estos les cobija leyes, que cada vez se hacen más presente para su protección, finamente este trabajo se realizó para comprender el proceso de responsabilidad civil de los profesionales de la medicina en el ejercicio de su especialidad.

\section{Referencias}

[1] M.O. Pérez Pulido, G.O. Merli, J. Ramoni Perazzi, y M. Valbuena Vence, "Evaluación de la calidad en la prestación de servicios de Salud por medio de series de tiempo enmarcado en la metodología Seis Sigma”, Eco matemático, vol. 8, pp. 73-77, ene. 2017

[2] J.A. Colmenares-Jiménez. "La responsabilidad jurídica del médico en Venezuela", Revista de Derecho, vol 23, pp 289-305, junio 2005.

[3] JH. Capitant. Vocabulario jurídico. Buenos Aires: Depalma, 1979.

[4] W. Ruiz, "La responsabilidad médica en Colombia", Criterio jurídico, vol, 4, pp. 195216, 2004.

[5] S.R. Sotomarino, "Una mirada a la responsabilidad profesional originada de la práctica médica", Revista Pólemos, vol. 1, septiembre 2015.

[6] C. Jaramillo-Sierra y P.N. Robles-Bacca, "La reparación del daño extrapatrimonial a la persona por incumplimiento contractual: la experiencia colombiana". Revista Chilena de Derecho Privado, no. 26, Enero-Junio, 2014

[7] P. López-Díaz, “Obligaciones y responsabilidad civil”. Revista Chilena de Derecho Privado, no. 28, pp. 307-321, Julio 2017

[8] R. Aguiar-Guevara, Tratado de Derecho Médico. 2da Ed. Lima: Legislación Económica, 2007

[9] A. Urdaneta-Morales, "El daño médico y su responsabilidad derivada: implicaciones civiles 32, pp. 165-183. Enero-Diciembre, 2015

[10] J.Tamayo-Jaramillo. Tratadoderesponsabilidad civil, Tomo II, 2da Ed. Colombia: Legis 


\section{2}

[11] C.D. Acosta-Madiedo, "Responsabilidad médica: elementos, naturaleza y carga de la prueba." Anuario de Derecho Privado, vol. 43, pp. 1-26, 2010

[12] J. Tamayo- Jaramillo. Sobre la prueba de la culpa médica. Colombia: Diké, 2001

[13] L. Bustamante. Y. Fernández. A. Fernández, y L. Fernández, "Responsabilidad profesional en el Ejercicio de la Medicina en Venezuela", 2012. [En línea]. Disponible en: https://www. monografias.com/trabajos93/responsabilidadprofesional-ejercicio-medicina-venezuela/ responsabilidad-profesional-ejerciciomedicina-venezuela.shtml

[14] M. Carles, "Responsabilidad por una práctica médica inadecuada: una perspectiva económica". Gaceta Sanitaria, vol.17 no.6, pp. 494-503, nov-dic. 2003.

[15] A.L. Villegas-Mora, "Responsabilidad civil profesional del médico". Revista Médica de Costa Rica y Centroamérica, vol. LXX, no. 607, pp. $389-393,2013$ 